\title{
The lolB gene in Xanthomonas campestris pv. campestris is required for bacterial attachment, stress tolerance, and virulence
}

\author{
Chao-Tsai Liao, Chih-En Li, Hsiao-Ching Chang, Chien-Hui Hsu, Ying-Chuan Chiang and Yi-Min Hsiao*
}

\begin{abstract}
Background: Xanthomonas campestris pv. campestris (XCC) is a Gram-negative bacterium that can cause black rot disease in crucifers. The lipoprotein outer membrane localization (Lol) system is involved in the lipoprotein sorting to the outer membrane. Although Xcc has a set of annotated lol genes, there is still little known about the physiological role in this phytopathogen. In this study, we aimed to characterize the role of LolB of Xcc in bacterial attachment, stress tolerance, and virulence.

Results: To characterize the role of LolB, IOIB mutant was constructed and phenotypic evaluation was performed. The IOIB mutant revealed reductions in bacterial attachment, extracellular enzyme production, and virulence. Mutation of $I O / B$ also resulted in reduced tolerance to a myriad of stresses, including heat and a range of membrane-perturbing agents. Trans-complementation of $/ O / B$ mutant with intact $/ O / B$ gene reverted these altered phenotypes to the wildtype levels. From subsequent reporter assay and reverse transcription quantitative real-time polymerase chain reaction (RT-qPCR) analysis, the expression of genes that encode the major extracellular enzymes and the stress-related proteins was reduced after $/ O / B$ mutation.
\end{abstract}

Conclusions: The results in this work contribute to the functional understanding of $/ O / B$ in Xanthomonas for the first time, and provide new insights into the function of Io/B in bacteria.

Keywords: Xanthomonas campestris, Stress tolerance, Virulence

\section{Background}

In Gram-negative bacteria, the outer membrane presents a selectively permeable barrier to the environment and is the first line of defense against harmful chemicals, including detergents and antibiotics [1]. Bacterial lipoproteins are a set of membrane proteins localized on either leaflet of the lipid bilayer and are important components of the Gram-negative cell envelope [2, 3]. In Escherichia coli, most lipoproteins are considered to be anchored to the inner leaflet of the outer membrane $[3,4]$. The Lol

*Correspondence: ymhsiao@ctust.edu.tw

Department of Medical Laboratory Science and Biotechnology, Central

Taiwan University of Science and Technology, Taichung, Taiwan (lipoprotein outer membrane localization) pathway is responsible for sorting and localizing lipoprotein [2-5].

The Lol pathway has components in each compartment of the cell envelope: an ATP binding cassette transporter LolCDE in the inner membrane; a soluble chaperone protein LolA in the periplasmic space; and a lipoprotein LolB in the outer membrane [4]. The outer membranedirected lipoprotein is extracted from the inner membrane by LolCDE, transferred to LolA, and shuttled to the outer membrane, where LolB receives and then anchors them into the bilayer [2-5]. The Lol proteins of $E$. coli have been studied in depth and each of the $l o l$ genes are considered to be essential for viability of this bacterium $[2,3,5]$. 
The Lol homologues can be found in many Gram-negative bacteria, suggesting that the pathway is conserved $[2,3,5]$. However, conservation of individual Lol protein encoding genes varies. In most $\gamma$-proteobacteria, the LolCDE consists of one copy each of membrane subunits LolC and LolE, and two copies of LolD [3]. LolC and LolE are homologues but cannot functionally substitute each other in E. coli [6]. However, some bacterial genomes contain only one copy of a lolC/lolE gene; the protein product contains sequence motifs of both LolC and LolE and the LolF name was proposed to distinguish such proteins from obvious LolC and LolE homologues [7]. Additionally, phylogenetic analysis suggests that $l o l B$ gene is only conserved in $\beta$ - and $\gamma$-proteobacteria $[2,5]$. Till now, only the Lol proteins of Pseudomonas aeruginosa have been indicated to involve in the sorting of outer membrane lipoprotein, as in the case of $E$. coli lipoproteins $[8,9]$. Recently, it has been reported that the LolCDE proteins of the pathways of E. coli and P. aeruginosa are interchangeable [10].

Xanthomonas campestris pv. campestris (Xcc), a Gramnegative bacterium, is capable of causing cruciferous plant infections. This pathogen causes black rot disease in the members of Brassica oleracea such as broccoli, cabbage, cauliflower, and radish [11-13]. The virulence of $X c c$ depends on a number of factors, including biofilm formation, extracellular enzymes (such as cellulase, mannanase, and protease), and extracellular polysaccharides $[14,15]$. Four lol genes (lolA, lolB, lolD, and lolF) have been annotated in the fully sequenced $X c c$ genome [12, 16-18]. Among them, only lolA has been studied. The Xcc lolA has been indicated to play a role in pathogenicity and stress tolerance [19]. The aims of the present work are to characterize lolB in Xcc. The role of lolB in bacterial attachment, extracellular enzyme production, stress tolerance, and virulence was examined in this study.

\section{Methods}

\section{Bacterial strains and growth conditions}

Table 1 lists the bacterial strains and plasmids used in this study. E. coli and $X c c$ were grown at $37^{\circ} \mathrm{C}$ and $28^{\circ} \mathrm{C}$, respectively. Luria-Bertani (LB) was used as a routinely cultured medium [20]. XOLN was a basal salt medium and contained $0.625 \mathrm{~g} / \mathrm{L}$ tryptone and $0.625 \mathrm{~g} / \mathrm{L}$ yeast

Table 1 Bacterial strains and plasmids used in this study

\begin{tabular}{|c|c|c|}
\hline Strain or plasmid & Description & Reference or source \\
\hline \multicolumn{3}{|l|}{ E. coli } \\
\hline $\mathrm{ECOS}^{\mathrm{TM}} 101$ & $\begin{array}{l}\text { endA1 recA1 relA1 gyrA96 hsdR17 }\left(r_{\mathrm{K}}{ }^{-}, m_{\mathrm{K}}{ }^{+}\right) \text {phoA supE44 thi-1 } \triangle(\text { lacZYA-argF }) \text { U169 } \varphi 80 \triangle(\text { lacZ)M15 } \\
\mathrm{F}^{-}\end{array}$ & Yeastern \\
\hline \multicolumn{3}{|c|}{ X. campestris pv. campestris } \\
\hline $\mathrm{XC17}$ & Virulent wild type strain isolated in Taiwan, $A p^{R}$ & {$[22]$} \\
\hline CL17 & XC17-derived mutant with EZ-Tn5 inserted in IolB gene, $A p^{R}, \mathrm{Km}^{R}$ & This study \\
\hline \multicolumn{3}{|l|}{ Plasmid } \\
\hline yT\&A & PCR cloning vector, $A p^{R}$ & Yeastern \\
\hline pTlolB & $\begin{array}{l}\text { A } 790 \text { bp RCR amplified fragment from IolB (nucleotides }-133 \text { to }+657 \text { relative to the translation } \\
\text { start site) and cloned into yT\&A }\end{array}$ & This study \\
\hline pUC19G & $\mathrm{Gm}^{\mathrm{R}}$ cartridge from pUCGM ligated with the blunt-ended Avall-Sspl large fragment from pUC19 & [23] \\
\hline pUClolB & $\begin{array}{l}\text { The } 790 \text { bp BamHI-EcoRl fragment of the pTlolB cloned into the BamHI and EcoRl sites of } \\
\text { pUC19G }\end{array}$ & This study \\
\hline pUClolBK & pUClolB derivative with $\mathrm{Km}^{\mathrm{R}}$ inserted in the internal region of $/ \mathrm{O} / \mathrm{B}$ gene & This study \\
\hline pRK415 & Broad-host-range vector, RK2 ori, $\mathrm{Tc}^{\mathrm{R}}$ & {$[24]$} \\
\hline pRKIolB & The $790 \mathrm{bp}$ BamHI-EcoRl fragment of the pTlolB cloned into the BamHI and EcoRI sites of pRK415 & This study \\
\hline pFY13-9 & Promoter-probing vector derived from pRK415, using lacZ as the reporter, $T c^{R}$ & {$[25]$} \\
\hline pFYengA & $\begin{array}{l}\text { The 159-bp fragment, }-181 /-23 \text { relative to engA translation start site, cloned into the Pstl/Xbal } \\
\text { sites of pFY13-9 }\end{array}$ & This study \\
\hline pFYmanA & $\begin{array}{l}\text { The } 360 \text {-bp fragment, }-372 /-13 \text { relative to manA translation start site, cloned into the Pstl/Xbal } \\
\text { sites of pFY13-9 }\end{array}$ & This study \\
\hline pFYprt1 & $\begin{array}{l}\text { The } 313-b p \text { fragment, }-392 /-80 \text { relative to prt1 translation start site, cloned into the Pstl/Xbal } \\
\text { sites of pFY13-9 }\end{array}$ & {$[26]$} \\
\hline pFYclpP1 & $\begin{array}{l}\text { The } 375-\mathrm{bp} \text { fragment, }-384 /-10 \text { relative to } \mathrm{clpP} \text { translation start site, cloned into the } \mathrm{Xhol} / \mathrm{Xbal} \\
\text { sites of pFY13-9 }\end{array}$ & {$[27]$} \\
\hline pFYclpX & $\begin{array}{l}\text { The 327-bp fragment, }-336 /-10 \text { relative to } c / p X \text { translation start site, cloned into the Xhol/Xbal } \\
\text { sites of pFY13-9 }\end{array}$ & This study \\
\hline
\end{tabular}

$\mathrm{Ap}^{\mathrm{R}}$, ampicillin-resistant; $\mathrm{Gm}^{\mathrm{R}}$, gentamycin-resistant; $\mathrm{Km}^{\mathrm{R}}$, kanamycin-resistant; $\mathrm{TC}^{\mathrm{R}}$, tetracycline-resistant 
extract [21]. Glucose or glycerol was added (2\%) as required. Liquid cultures were shaken at $180 \mathrm{rpm}$. Solid media contained $1.5 \%$ agar. Growth media was supplemented with antibiotics when required. The added antibiotics and concentrations are: ampicillin $(50 \mu \mathrm{g} / \mathrm{mL})$, gentamycin $(15 \mu \mathrm{g} / \mathrm{mL})$, kanamycin $(50 \mu \mathrm{g} / \mathrm{mL})$, and tetracycline $(15 \mu \mathrm{g} / \mathrm{mL})$.

\section{Recombinant DNA techniques}

Bacterial genomic DNA and plasmid DNA were purified using the Wizard ${ }^{\circledR}$ Genomic DNA Purification Kit (Promega) and the Gene-Spin ${ }^{\mathrm{TM}}$ Miniprep Purification Kit (Protech), respectively. Polymerase chain reaction (PCR) was carried out as previously described [28]. Table 2 lists the primers used in this study. Standard protocols for agarose gel electrophoresis, DNA ligation, restriction digestion, and $E$. coli transformation were as described previously [29]. Transformation of Xcc was achieved through electroporation [30]. The sequence of DNA fragment was determined by Mission Biotech Co., Ltd. (Taipei, Taiwan).

\section{IolB mutant construction and complementation}

For the construction of lolB mutant, the 790-bp BamHIEcoRI fragment containing the upstream 133-bp and the entire coding region of the $\mathrm{XC17}$ lolB was PCRamplified using primers lolBF/lolBR and cloned into the $\mathrm{yT} \& \mathrm{~A}$ (Yeastern) to produce pTlolB. After sequence verification, the fragment was excised and cloned into the BamHI-EcoRI sites of pUC19G [23] to generate

Table 2 Primers used in this study

\begin{tabular}{|c|c|}
\hline Primer & Sequence $\left(5^{\prime} \text { to } 3^{\prime}\right)^{a}$ \\
\hline \multicolumn{2}{|c|}{ IolB gene (mutant construction, confirmation and complementation) } \\
\hline IolBF/lolBR & $\underline{\text { GGATCCAAATCGCCGCGCACGTGGGT/GAATTCAGGGCGAGAGCGTCCATTGG }}$ \\
\hline \multicolumn{2}{|c|}{ Extracellular enzyme encoding genes (promoter analysis and RT-qPCR) } \\
\hline \multicolumn{2}{|l|}{ engA gene } \\
\hline 844pstF/1002xbaR & $\begin{array}{l}\text { AACTGCAGCCTGCGGACAGCGCGCAGGGGG/GCTCTAGAGCTCGACACCCGA } \\
\text { GCGCGGTAA }\end{array}$ \\
\hline engAF/engAR & GTGTGAACGTGTTCGGCTTC/TCATGTCCTTCCAGTTGCGT \\
\hline \multicolumn{2}{|l|}{$\operatorname{man} A$ gene } \\
\hline $61 \mathrm{pstF} / 420 x \mathrm{baR}$ & 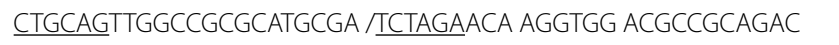 \\
\hline manAF/manAR & AGTTCTACATGCGCGACAAC/CGTACATGTGCACGCTGAAA \\
\hline \multicolumn{2}{|l|}{ prt1 gene } \\
\hline 200pstF/512xbaR & $\begin{array}{l}\text { AACTGCAGTGTCGCTGCGCCAGGAGCTGAC/GCTCTAGACGGATCGCCCCT } \\
\text { GTTATCGATC }\end{array}$ \\
\hline prt1F/prt1R & CACCGCACAGACCCATCAGA/TTACCAGTTCCGGCCCCAAC \\
\hline \multicolumn{2}{|c|}{ Stress tolerance related genes (promoter analysis and RT-qPCR) } \\
\hline \multicolumn{2}{|l|}{ clpP gene } \\
\hline 1315Xhol/1689Xbal & CTCGAGGGGTTCATGGACGCCGCT/ICTAGATGTTGTGGCAGCGGCCTGTG \\
\hline $\mathrm{clpPF} / \mathrm{clpPR}$ & AGATCCTGACCTTGCGTTCG/CTTGAAGTTGTCGCGTTCGG \\
\hline \multicolumn{2}{|l|}{ clpX gene } \\
\hline 114xhoF/440xbaR & $\underline{\text { CTCGAGGCGACCGATATCGACATCCA/ICTAGACCCAGTTACCCCACCCGATG }}$ \\
\hline $\mathrm{clpXF/clpXR}$ & CTCGAGGAACTCGATGAGCC/AGCTCCACGCTTTCCATCTC \\
\hline \multicolumn{2}{|c|}{ Putative lipoprotein encoding genes (RT-qPCR) } \\
\hline 0253F/0253R & GCAATTACCAGCTGCGCTAC/TTGGTGACATCCTCGAACGG \\
\hline 0677F/0677R & GGCGACTTCAATTGCTACCG/GCACCAGTTTCCATAACGCC \\
\hline 0679F/0679R & GCCGATTTCAACAAGGCCAA/TTCGTCGTTGGGAAAGGTCT \\
\hline 0707F/0707 R & GGGTCATCGACCTGAGCTAC/CGCGTACCTCGACATTACCG \\
\hline 1519F/1519R & GCCTACGTGTGGAACGAACA/CGGTCATGGTCGAACTGCAT \\
\hline $1584 F / 1584 R$ & CGACAGACGCTGTACGAAGA/TATTGACGCGTGCAAAGTGC \\
\hline $3831 F / 3831 R$ & TGAAGATCCACTGGGCCGTA/TTCGGGTTTCTGCTCGGTC \\
\hline $4152 F / 4152 R$ & CGCAATGTGCCATTGGTGAT/CTCCGTGGTATCGAACAGGC \\
\hline \multicolumn{2}{|l|}{ 16S rRNA gene (RT-qPCR) } \\
\hline $16 S F / 16 S R$ & GTAAAGCGTGCGTAGGTGGT/CGTGCCTCAGTGTCAGTGT \\
\hline
\end{tabular}

${ }^{a}$ : Added restriction enzyme sites are underlined 
pUClolB. The EZ-Tn $5^{\mathrm{TM}}<\mathrm{KAN}-2>$ Transposon $\left(\mathrm{Km}^{\mathrm{R}}\right.$, $1221 \mathrm{bp})$ was randomly inserted into pUClolB using the $\mathrm{EZ}-\mathrm{Tn} 5^{\mathrm{TM}}<\mathrm{KAN}-2>$ insertion kit according to the manufacturer's instructions (Lucigen). One plasmid, pUClolBK, with the transposon inserted into the lolBcoding sequence at $326 \mathrm{bp}$ from the translational start site was used for mutant construction. This plasmid was then introduced into the $\mathrm{Xcc}$ wild-type $\mathrm{XC17}$ by electroporation, allowing for double crossover, and transformants were selected on LB medium supplemented with kanamycin (transposon selection marker). Insertion of transposon into lolB gene was confirmed by PCR. The confirmed lolB mutant was designated as CL17.

For complementation of the lolB mutant, the 790bp BamHI-EcoRI fragment of pTlolB was excised and inserted into the BamHI-EcoRI sites of pRK415 [24]. The generated plasmid $\mathrm{pRKlolB}$ was transferred into the $l o l B$ mutant strain CL17 by electroporation, giving the complemented strain CL17(pRKlolB). For phenotypic comparison, the empty vector pRK415 was introduced into $\mathrm{XC17}$ and $\mathrm{CL} 17$, giving transformants $\mathrm{XC17}(\mathrm{pRK} 415)$ and CL17(pRK415) in parallel.

\section{Assays of bacterial attachment and pathogenicity}

The bacterial attachment was evaluated by examining the ability of cells to adhere to the 96-well polystyrene microtiter plates (Nunc) and cabbage leaves surface as the previously described method [31]. The experiments were done at least three times. The pathogenicity of Xcc to host plant cabbage was tested by leaf-clipping method [26] and the disease symptoms in cabbage were photographed and lesion lengths were measured 14 days after inoculation. Testing was performed in three independent experiments, each with six replicates.

\section{Extracellular enzyme activity analysis}

Extracellular enzyme activity was analyzed by spotting $3 \mu \mathrm{L}$ of overnight culture $\left(\mathrm{OD}_{550}=1\right)$ onto XOLN agar plates containing the appropriate substrates. The substrates used are: carboxymethyl cellulose $(0.5 \%$, substrate for cellulase), locus bean gum ( $0.2 \%$, for mannanase), and skimmed milk (1\%, for protease). After 2 days (cellulase and mannanase) or 3 days (protease) of incubation, enzyme activity was determined as described previously [32]. Each test was carried out at least three replicates.

\section{Stress tolerance assay}

Stress tolerance was tested by inoculating overnight culture into fresh XOLN medium containing glycerol to obtain an initial $\mathrm{OD}_{550}$ of 0.35 in the absence or presence one type of stress condition. The stresses and their concentrations used were as following: EDTA $(0.2 \mathrm{mM})$, $\mathrm{H}_{2} \mathrm{O}_{2}(0.005 \%)$, polymyxin $\mathrm{B}(2 \mu \mathrm{g} / \mathrm{mL})$, puromycin
$(10 \mu \mathrm{g} / \mathrm{mL})$, and sodium dodecyl sulfate (SDS, $0.0075 \%)$. The growth of each strain was determined by measuring the $\mathrm{OD}_{550}$ values after incubation with shaking $(180 \mathrm{rpm})$ at $28{ }^{\circ} \mathrm{C}$ for $24 \mathrm{~h}$. The method for temperature tolerance assay was according to previously study [31]. Each stress test was repeated at least three times.

\section{Cell membrane integrity analysis}

The integrity of Xcc cell membrane was examined by the SYBR Green I/propidium iodide (PI) viability assay as the previously described methods [33, 34] with some modifications. Briefly, the cultured bacteria were harvested by centrifuging at $12,000 \mathrm{rpm}$ for $2 \mathrm{~min}$ and washed twice then resuspended in sterile $0.85 \% \mathrm{NaCl}$. The final cell suspension was adjusted to an $\mathrm{OD}_{550}=1$. Then, the bacterial cells $(100 \mu \mathrm{L})$ were stained with SYBR Green I $(2 \mathrm{X}, 100 \mu \mathrm{L})$ and PI $(250 \mathrm{mg} / \mathrm{mL}, 10 \mu \mathrm{L})$. The samples were incubated for $40 \mathrm{~min}$ in dark at room temperature. After staining, the samples were washed twice and resuspended in $50 \mu \mathrm{l} 0.85 \% \mathrm{NaCl}$, and $5 \mu \mathrm{l}$ of this sample was trapped in between coverslip and glass slide. The slide was viewed under a fluorescence microscope.

\section{Reporter plasmid construction and promoter activity analysis}

Reporter constructs (pFYengA, pFYmanA, and pFYclpX) were generated by cloning the PCR-amplified upstream regions of engA, man $A$, and $\operatorname{clp} X$ into pFY13-9 [25], with lac $Z$ as the reporter. Briefly, the upstream region of each gene was amplified by PCR using primers 844pstF/1002xbaR for the engA gene, 61pstF/420xbaR for manA gene, and $114 x h o F / 440 x b a R$ for the clpX gene. Then, the PCR fragments were cloned into pFY13-9, giving rise to $\mathrm{pFYengA}, \mathrm{pFYmanA}$, and $\mathrm{pFYclpX}$. Reporter constructs pFYprt1 and pFYclpP1 containing the upstream regions of $p r t 1$ and $c l p P$, respectively, were obtained as previously described [26, 27]. Xcc strains harboring these constructs were grown overnight and inoculated into fresh media to obtain an initial $\mathrm{OD}_{550}$ of 0.35 , after which growth was allowed to continue. Samples were taken in triplicate at designated intervals and the $\beta$-galactosidase activity was assayed as previously described, with the enzyme activity expressed in Miller units [20].

\section{RNA isolation, reverse transcription (RT), and quantitative real-time PCR (qPCR)}

Total RNA was isolated from bacteria grown to the midexponential phase $\left(\mathrm{OD}_{550}=0.6\right)$ in XOLN medium supplemented with $2 \%$ glycerol using the RNeasy Mini Kit (Qiagen) according to provided instructions. The isolated RNA $(1 \mu \mathrm{g})$ was reverse-transcribed to cDNA using the iScript $^{\mathrm{TM}}$ gDNA Clear cDNA Synthesis Kit (BIO-RAD). 
qPCR was performed using $\mathrm{iQ}^{\mathrm{TM}} \mathrm{SYBR}^{\circledR}$ Green Supermix in a CFX96 Real Time PCR system (BIO-RAD). The PCR amplification conditions were as follows: $3 \mathrm{~min}$ at $95^{\circ} \mathrm{C}$, followed by 40 cycles of $10 \mathrm{~s}$ at $95{ }^{\circ} \mathrm{C}, 10 \mathrm{~s}$ at $60{ }^{\circ} \mathrm{C}$, and $30 \mathrm{~s}$ at $72{ }^{\circ} \mathrm{C}$. Table 2 lists the sequences of primer sets of the tested target genes. The Xcc $16 S$ rRNA gene was used for normalization. All qPCRs were performed at least three times. The fold change for transcript was calculated by the $2^{-\Delta \Delta C t}$ method.

\section{Statistical analysis}

Each experiment was carried out at least three repeats. Values are the averages of three replications per experiment. Student's $t$ test was used to evaluate the statistical significance of differences between averages. A $p$ value $<0.05$ was considered statistically significant.

\section{Results}

Disruption of IolB leads to decrease bacterial attachment In the genome of Xcc strain XC17, the locus_tag AAW18_ RS04315 is annotated to encode lipoprotein insertase outer membrane protein LolB (Gen-Bank accession no. NZ_CP011946) [16]. The XC17 lolB open reading frame is $657 \mathrm{bp}$ in length and is located in the genome sequence at positions 1,003,373-1,004,029 [16]. The XC17 lolB gene are found in several sequenced $X c c$ strains, such as ATCC33913, 8004, and B100 [12, 17, 18]. Through sequence comparison, it was found that the coding product of $\mathrm{XC17}$ lolB was identical in both amino acid sequence and size to LolBs from Xcc strains ATCC33913 and 8004. The orthologous gene of lolB was also highly conserved in other members of Xanthomonas, such as $X$. campestris pv. raphani $756 \mathrm{C}$ [35], $X$. campestris pv. vesicatoria 85-10 [36], $X$. citri subsp. citri (formerly $X$. axonopodis pv. citri) 306 [18], X. hortorum pv. gardneri ICMP 7383 [37], and X. oryzae pv. oryzae KACC10331
[38] (Table 3). Although the lolB gene has been found in several members of Xanthomonas, none of them has been characterized with regard to function, and no relevant studies were found in the literature.

To explore the physiological role of $l o l B$ in $X c c$, the lolB mutant and its complemented strain were generated. Biofilm formation was tested on polystyrene microtiter plate (Fig. 1a), and leaf surface (Fig. 1b). As depicted in Fig. 1, it was indicated that the $\operatorname{lol} B$ mutant exhibited reduced attachment ability compared with the parental strain, and complementation of lolB mutant with plasmid pRKlolB (with intact lolB gene cloned in pRK415) could restore the adhesion ability to the wild-type level.

\section{The $I o l B$ gene is required for the full virulence of $X c c$}

To determine whether mutation of lolB caused loss of pathogenicity, lolB mutant was used to infect host plant cabbage by leaf-clipping method. At 14 days post inoculation, typical V-shaped black rot symptoms were found on leaves inoculated with the wild-type strain (Fig. 2a) and the lesion lengths were about $1.84 \mathrm{~cm}$ (Fig. 2b). However, the lolB mutant shown reduced virulence compared with the wild-type strain (Fig. 2a) and the lesion lengths caused by the mutant were about $0.45 \mathrm{~cm}$ (Fig. 2b). The complementation of $l o l B$ mutant with pRKlolB partially restored the virulence of the mutant (Fig. 2a). Although the complementary strain cannot fully restore pathogenicity, its consequent mean lesion length $(0.93 \mathrm{~cm})$ was significantly longer than that inoculated with the mutant strain (Fig. 2b). These results indicated that lolB is important for host virulence of Xcc.

\section{The lolB gene is involved in extracellular enzyme production}

It has been indicated that extracellular enzymes and extracellular polysaccharides contribute to the virulence

Table 3 LolB homologues in Xanthomonas spp

\begin{tabular}{|c|c|c|c|c|}
\hline Bacteria $^{a}$ & Gene ID & Predicted product & Size (aa) & Identities (\%) \\
\hline X. campestris pv. campestris ATCC 33913 & XCC0870 & Outer membrane lipoprotein precursor & 218 & 100 \\
\hline X. campestris pv. campestris 8004 & XC_3360 & Outer membrane lipoprotein precursor & 218 & 100 \\
\hline X. campestris pv. campestris B100 & Xccb100_3479 & Outer membrane lipoprotein receptor LolB & 218 & 99.1 \\
\hline X. campestris pv. raphani $756 C$ & XCR_1061 & Outer membrane lipoprotein LolB & 218 & 98.6 \\
\hline X. campestris pv. vesicatoria $85-10$ & XCV0978 & Outer membrane lipoprotein receptor LolB & 217 & 84.4 \\
\hline X. axonopodis pv. citri 306 & XAC0947 & Outer membrane lipoprotein precursor & 217 & 85.3 \\
\hline X. hortorum pv. gardneri ICMP 7383 & B1317_05530 & Lipoprotein localization factor LolB & 218 & 85.6 \\
\hline X. oryzae pv. oryzae KACC10331 & X003605 & Outer membrane lipoprotein precursor & 217 & 84.4 \\
\hline
\end{tabular}

a : X. campestris pv. campestris ATCC33913 (GenBank accession number: AE008922); X. campestris pv. campestris 8004 (CP000050); X. campestris pv. campestris B100 (AM920689); X. campestris pv. raphani 756C (CP002789); X. axonopodis pv. citri 306 (AE008923); X. hortorum pv. gardneri ICMP 7383 (CP018731); X. campestris pv. vesicatoria 85-10 (AM039952); X. oryzae pv. oryzae KACC10331 (AE013598)

b : According to a BLASTP search 
a

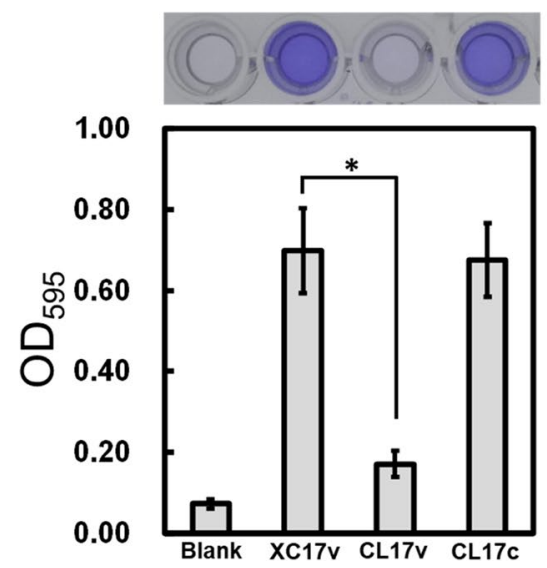

b

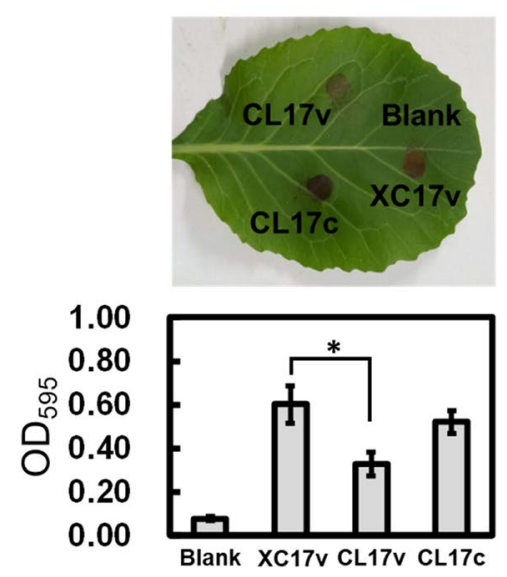

Fig. 1 Effects of mutation of lolB on cell attachment to polystyrene plates (a) and cabbage leaf surfaces (b) in Xcc. Strains to be tested were grown overnight, washed, and diluted using fresh XOLN medium supplemented with glucose, and were assayed as described in the Material and methods section. XC17v: wild-type strain XC17 carrying empty vector pRK415; CL17v: IolB mutant CL17 carrying pRK415; CL17c: complemented lolB mutant; Blank: XOLN medium supplemented with glucose without inoculation of bacteria. Values presented are the mean $\pm \operatorname{standard~deviation~}(n=3)$. Significance was determined using the Student $t$ test $(*$ indicates significance at $p<0.05$ )

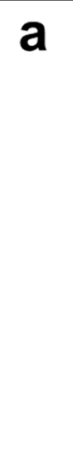

b

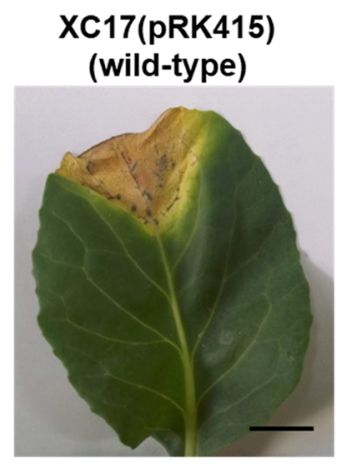

$1.84 \pm 0.23$

\section{CL17(pRK415) (IolB mutant)}

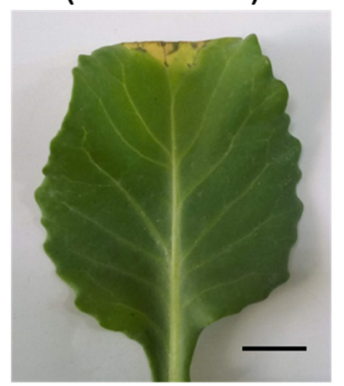

$0.45 \pm 0.10$

\section{CL17(pRKIolB)}

(complemented)

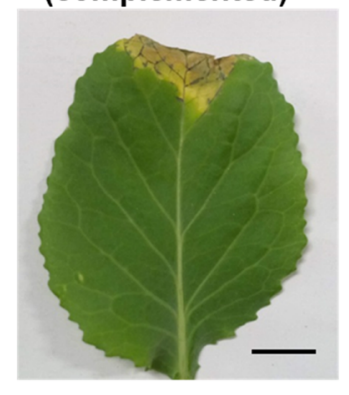

$0.93 \pm 0.10$

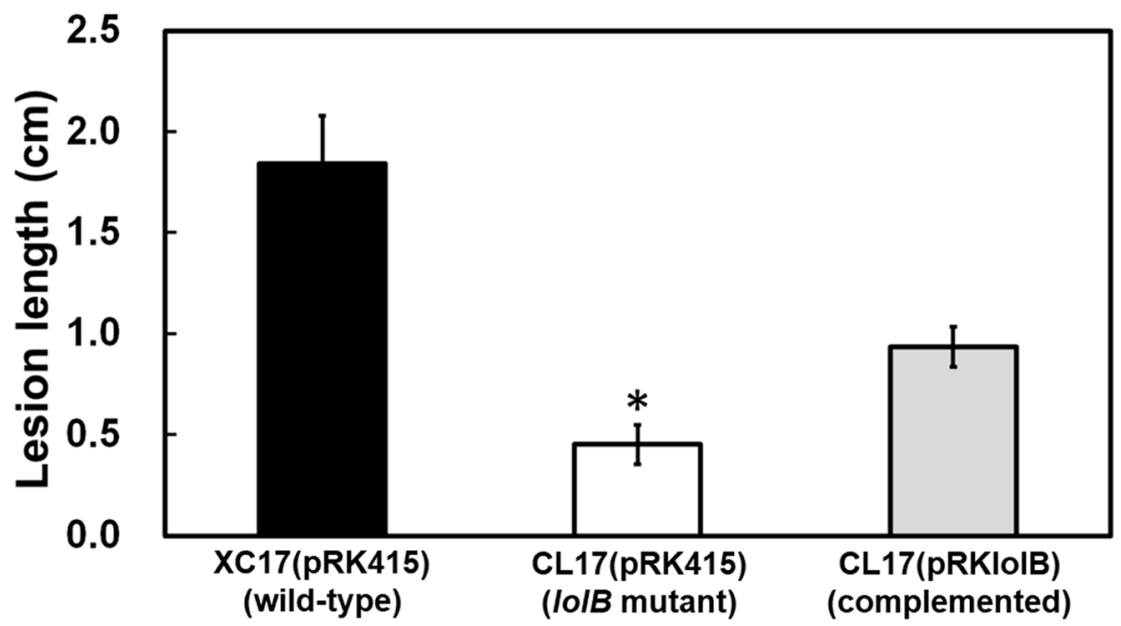

Fig. 2 Effects of mutation of IolB on virulence of Xcc in cabbage. (a) Black rot symptoms caused by Xcc strains on inoculated leaves of host cabbage plant. After 14 days inoculation, the photographs were taken. (b) Mean lesion lengths caused by different Xcc strains. Values shown are the average \pm standard deviation from three repeats, each with six leaves. Significance was determined using the Student $t$ test $\left(^{*}\right.$ indicates significance at $p<0.05)$ 
of $X c c[39,40]$. The reduced virulence of the lolB mutant (Fig. 2) suggested that the lolB gene has roles in the production of these pathogenicity-related determinants. The activity of extracellular hydrolytic enzymes (including cellulase, mannanase, and protease) was first tested. The results showed that the levels of extracellular cellulase and mannanase were reduced in the $l o l B$ mutant and could be restored by complementation (Fig. 3). In the protease assays, the diameters of the hydrolysis zones formed by the lolB mutant were significantly smaller than those found for the wild type and complementary strains. As the colony diameter of wild type are larger than those of lolB mutant and the complementary strain, lolB might be not involved in protease production, although small effects could not be excluded. Next, extracellular polysaccharide production was tested. The extracellular polysaccharide yields produced by the mutant were similar to those of the wild type (data not shown).

\section{The IolB mutant displays increased sensitivity to various stresses}

As several factors reported to influence bacterial attachment also have roles in stress tolerance in $X c c[19,31,41$, 42 ], we aimed to determine whether the $l o l B$ gene was required for stress adaptation of $X c c$. To examine whether lolB contributes to stress tolerance, the sensitivity of the lolB mutant together with the wild-type and complementary strains was evaluated under a range of stresses, including heat, EDTA, $\mathrm{H}_{2} \mathrm{O}_{2}$, polymyxin $\mathrm{B}$, puromycin, and SDS. At physiological temperature $\left(28^{\circ} \mathrm{C}\right)$, the tested strains plated at all densities grew normally (Fig. 4a, left). When bacterial strains grew at elevated temperature (37 $\left.{ }^{\circ} \mathrm{C}\right)$, the growth of $\operatorname{lolB}$ mutant was inhibited and this grow deficiency was restored by genetic complementation (Fig. 4a, right). When bacterial strains were exposed to EDTA, $\mathrm{H}_{2} \mathrm{O}_{2}$, polymyxin $\mathrm{B}$, and SDS, the lolB mutant exhibited significant growth reduction compared to the wild type and complementary strains (Fig. 4b). These data indicated that lolB is involved in stress in $X c c$.

\section{Mutation of $I o l B$ influences the expression of genes encoding extracellular enzymes and involved in stress tolerance}

Since mutation of lolB leads to reductions in bacterial attachment, extracellular enzyme production, and stress tolerance, lolB might be involved in expression of genes related to these phenotypes. Five genes (engA, manA, prt1, $c l p P$, and $\operatorname{clpX)}$ were selected based on the alternated mutant phenotypes mentioned above. Among them, engA (encodes major cellulase) [28, 40], manA (encodes major mannanase) [39, 43], and prt1 (encodes major protease) [40, 44] have been implicated as virulence factors. Both $\operatorname{clpP}$ and $\operatorname{clp} X$ (encode the proteolytic core and ATP-binding subunit of Clp protease, respectively) were known to play a role in extracellular enzyme production, stress tolerance, and virulence $[27,31]$. In addition, the $\operatorname{clp} X$ gene was also reported to be involved in bacterial attachment [31]. To evaluate the involvement of $l o l B$ in expression of these virulence-related genes, reporter constructs containing the upstream regions of these genes (pFYengA, pFYmanA, pFYprt1, pFYclpP1, and pFYclpX) were introduced into XC17 (wild type) and CL17 (lolB mutant), and the resultant strains were subjected to $\beta$-galactosidase assays. As depicted in Fig. $5 \mathrm{a}$, the $\beta$-galactosidase levels of CL17 harboring pFYengA, pFYmanA, pFYprt1, pFYclpP1, and pFYclpX were $64 \%$, $49 \%, 47 \%, 68 \%$, and $71 \%$ of the levels of XC17 carrying the same constructs. The effect of lolB mutation on the expression of these genes was also evaluated by RTqPCR. The results indicated that all of the tested genes were significantly reduced in the $l o l B$ mutant when compared with wild type (Fig. 5b). Taken together, both sets of expression results from the reporter assay and RT-qPCR analysis suggested $l o l B$ mutation affects the expression of engA, manA, prt1, $\operatorname{clpP}$, and $\operatorname{clpX}$.

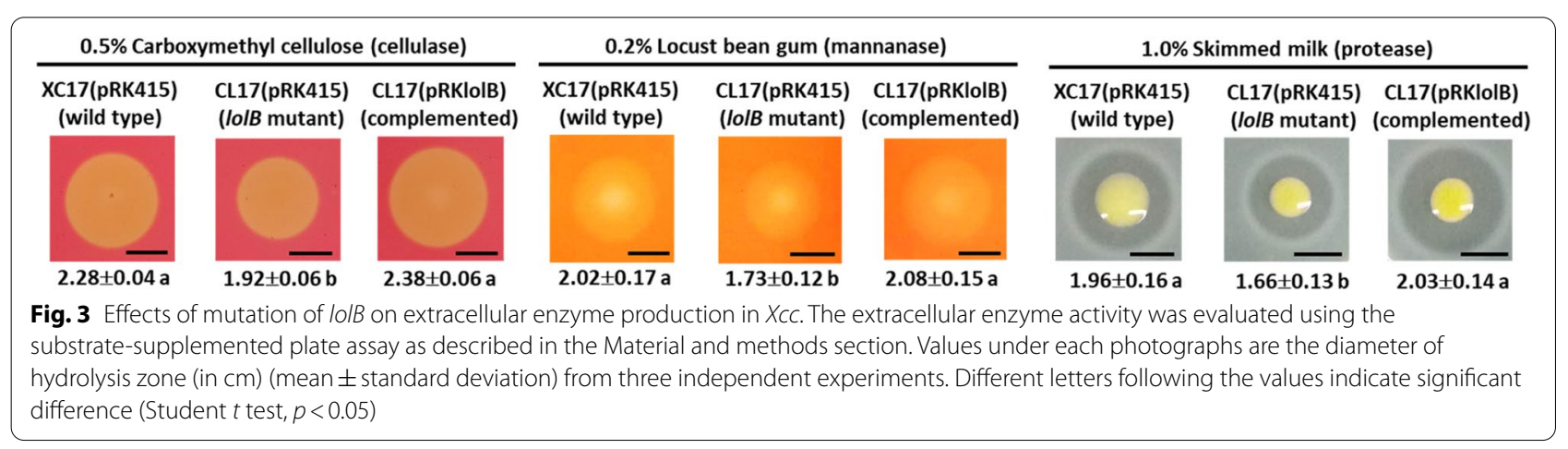


a

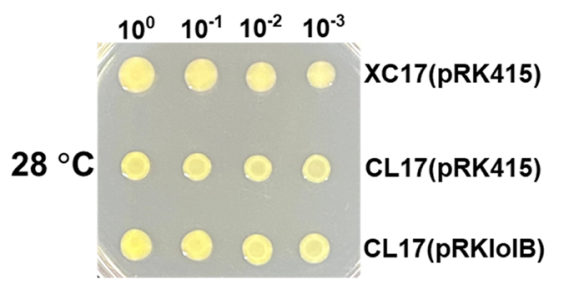

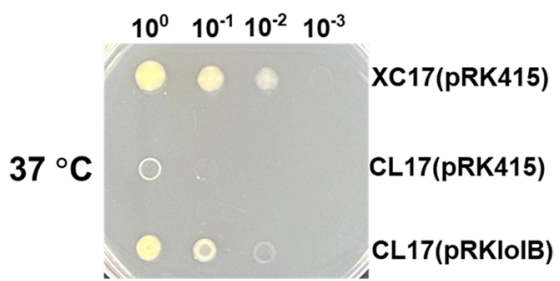

b

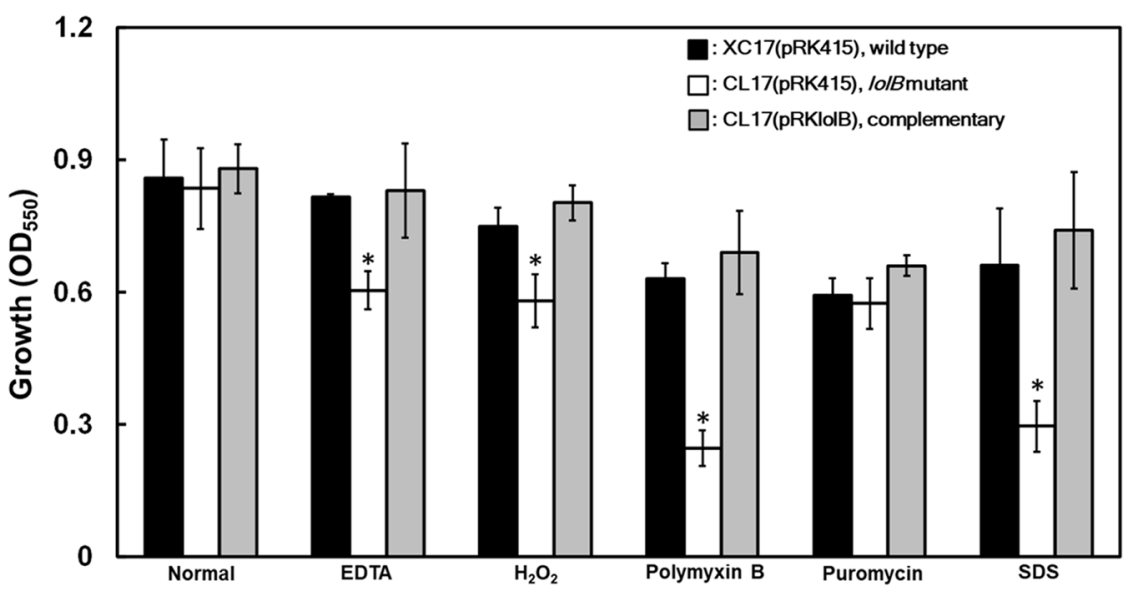

Fig. 4 Effects of mutation of IOIB on stress tolerance. (a) Heat tolerance was carried out with tenfold dilution of cells spotted on LB plate and incubated at $28^{\circ} \mathrm{C}$ or $37^{\circ} \mathrm{C}$ for 3 days. (b) The effects of a range of chemicals on bacterial growth were determined quantitatively in liquid culture. Bacteria cells were grown in XOLN medium with or without different stresses. After $24 \mathrm{~h}$, the cell density was determined at $\mathrm{OD}_{550}$. Values shown are the averages \pm standard deviations from three repeats. The asterisk $\left(^{*}\right)$ indicates $p<0.05$

\section{Mutation of $I O / B$ influences the expression of genes encoding putative lipoproteins and the integrity of cell membrane}

The findings showing reduced bacterial attachment and resistance to several membrane-perturbing compounds in lolB mutant, compared to the wild-type strain, might be due to an altered outer membrane lipoprotein profile and change in cell membrane integrity. Till now, the key amino acid residues involved in lipoprotein localization in Xcc remain unknown. According to DOLOP, a database of bacterial lipoproteins, 101 lipoproteins in the genome sequence of $X c c$ strain 8004 were identified [45]. To test the effects of $l o l B$ mutation on the expression of predicted lipoproteins, eight putative lipoprotein encoding genes are randomly selected, and the expression of these genes is evaluated by RT-qPCR. Table 4 shows that three genes, including $X C_{-} 0707, X C_{-} 1584$, and $X C_{-} 4152$, were not expressed differently in the $l o l B$ mutant and wildtype strains. However, the expression of five genes was significantly upregulated in the lolB mutant compared to the wild-type strain; they were genes encoding a dipeptidyl anmnopeptidase (XC_0253), a methanol dehydrogenase $\left(X C_{-}\right.$0679), an alkaline phosphatase $\left(X C_{-} 1519\right)$, and two hypothetical proteins $\left(X C_{-} 0677\right.$ and $\left.X C_{-} 3831\right)$.
For examining the cell membrane integrity, SYBR Green I and PI were used for double staining of nucleic acids. SYBR Green I is a green permeable dye that stains all live cells, whereas PI is a red impermeant dye that stains only dead or damaged cells with a compromised cell membrane [34]. Thus, live bacteria with intact membranes fluoresce green, while bacteria with damaged membranes fluoresce red. As shown in Fig. 6, it can be clearly seen that the wild type appeared predominantly green (indicating cells with intact membranes); whereas the lolB mutant appeared substantially red (demonstrating cells with damaged membranes).

\section{Discussion}

In the fully sequenced $X c c$ genome, four lol genes have been annotated to encode proteins constituted to form Lol system [12, 16-18]. Till now, only lolA has been studied [19]. The goal of the present study was to characterize the function of Xcc lolB. Through genetic complementation and phenotypic evaluation, it was demonstrated that in $X c c, l o l B$ is involved in various cellular processes, including bacterial attachment, extracellular enzyme production, pathogenesis, tolerance to a range 


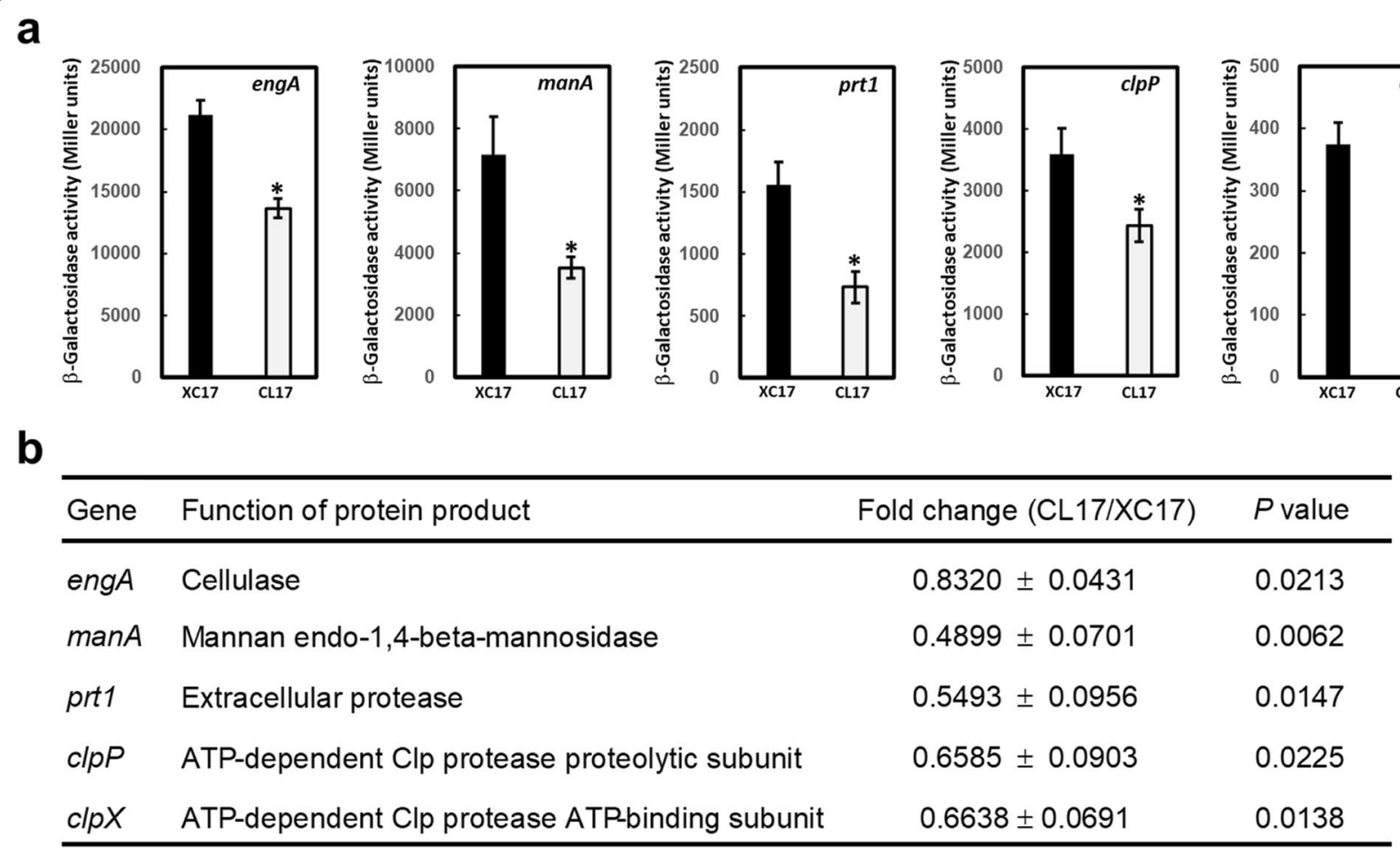

Fig. 5 Effects of mutation of lolB on the expression of genes coding for extracellular enzymes or products associated with stress tolerance. (a) B Galactosidase activities of XC17 (wild type, black bar) and CL17 (IolB mutant, gray bar) carrying pFYengA, pFYmanA, pFYprt1, pFYclpP1 and pFYclpX were determined. Tested strains were cultured in XOLN medium containing glycerol for $24 \mathrm{~h}$. Significance was determined by the Student $\mathrm{t}$ test ${ }^{*}$ indicates significance at $p<0.05$ ). (b) The expression level of extracellular enzyme genes (engA, manA, and prt 1 ) and stress tolerance-related genes $(c / p P$ and $c / p X)$ in the wild-type strain XC17 and IolB mutant strain CL17 was examined by RT-qPCR. The relative expression level of each test gene in XC17 and CL17 was normalized to its 165 rRNA content. Values shown are the average \pm standard deviation $(n=3)$

of environmental stresses, and the maintenance of cell membrane integrity.

The LolB homologues have been found in multifarious bacteria, and there are 1435 sequences with LolB domain (Pfam03550) are listed in the Pfam family database [46]. Among them, only the LolB of E. coli has been characterized in detail. In $E$. coli, lolB is an essential gene and deletion of $l o l B$ is lethal and causes accumulation of lipoprotein localization intermediates in the periplasm $[47,48]$. Via mutagenesis analysis, five conserved Trp residues (at positions 18, 52, 117, 148, and 183) of LolB were determined to affect membrane localization

Table 4 Comparison of expression of putative lipoprotein encoding genes in the wild type XC17 and the lo/B mutant CL17 by RT-qPCR

\begin{tabular}{|c|c|c|c|c|}
\hline Gene ID ${ }^{a}$ & Description & Predicted lipoprotein signal $^{b}$ & Fold change (CL17/XC17) ${ }^{c}$ & $p$ value \\
\hline XC_0253 & Dipeptidyl anmnopeptidase & MQRLLLASSLLLALSACSDKS & $3.1015 \pm 0.1651$ & 0.0361 \\
\hline XC_0677 & Hypothetical protein & MKYLLSAALCVAALSGCTDRE & $6.9535 \pm 0.4812$ & 0.0312 \\
\hline XC_0679 & Methanol dehydrogenase & MHQSSCRSARGGVLLMLALSAVLAGCKKDT & $5.3956 \pm 0.3450$ & 0.0348 \\
\hline XC_0707 & Rare lipoprotein A & MNSITGPKWLIPMALMLGLAACSSAP & $3.0953 \pm 0.2584$ & 0.0733 \\
\hline XC_1519 & Alkaline phosphatase & MPMRYRLPALAALTTLCVAACASTA & $1.7876 \pm 0.0305$ & 0.0177 \\
\hline XC_1584 & Cyanoglobin & MMTRWLRYSLLCVLTLSACATTQ & $3.0530 \pm 0.3839$ & 0.0615 \\
\hline XC_3831 & Hypothetical protein & MKIHWAVLACATLALAACQRPQ & $2.2654 \pm 0.1078$ & 0.0056 \\
\hline XC_4152 & Cytochrome $\mathrm{c}$ biogenesis protein & MARRFPWLWLGLLAACILVA & $3.4164 \pm 0.3353$ & 0.0581 \\
\hline
\end{tabular}

a : Gene ID is based on X. campestris pv. campestris strain 8004

b : According to the DOLOP database. The predicted lipobox with invariant cysteine is bold and underlined

$c:$ The relative expression level of each test gene in XC17 and CL17 was normalized to its $16 \mathrm{~S}$ rRNA content. Values shown are the average \pm standard deviation ( $n=3$ ) 


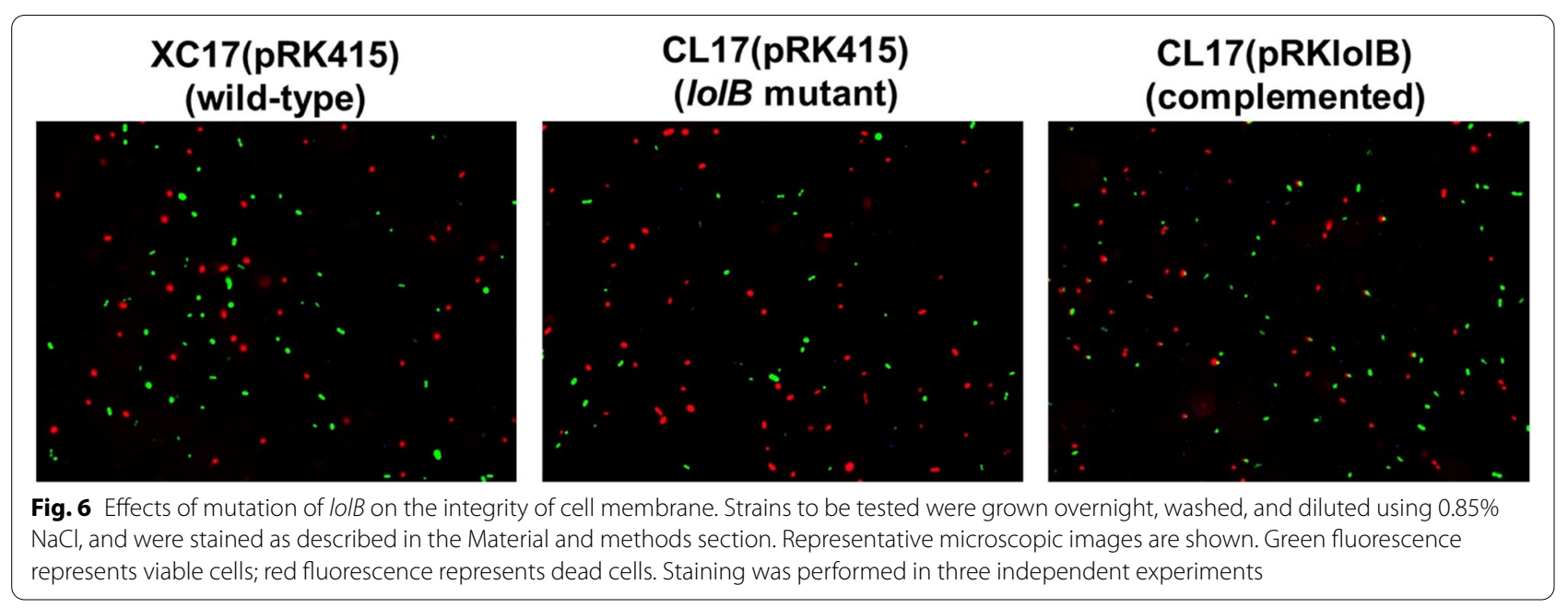

of E. coli lipoproteins [49], and Leu-68 in the protruding loop of LolB was also revealed to play critical roles in the membrane anchoring activity [50]. The Xcc LolB protein deduced from the gene contained 218 amino acids, with a typical $N$-terminal lipoprotein signal peptide, and the predicted signal peptidase II cleavage site was at $\mathrm{LSG}^{20}-\mathrm{C}^{21} \mathrm{~V}$ as predicted by signal P software [51]. Conserved domain search showed that it has a LolB domain located at residues 58-214 (bit score: 138.90; E-value: $4.2 \mathrm{e}-37$ ). The $X c c$ LolB had $25 \%$ identity and $41 \%$ similarity to $E$. coli LolB (encoded by $b 1209$ gene of E. coli K-12). Sequence analysis displayed that the aforementioned amino acid residues essential for the function of $E$. coli LolB were not fully conserved in Xcc LolB. The conserved amino acid residues included Trp-81, Trp-147, and Trp214, which corresponding to Trp-52, Trp-117, and Trp183 in E. coli LolB. The residues in comparable positions for Trp-18, Leu-68, and Trp-148 in E. coli LolB were substituted by Val-39, Val-96, and Ile-179 in Xcc LolB, respectively. The role of these residues in Xcc LolB function remains to be elucidated.

Apart from the observations that mutation in the lolB gene of $E$. coli affected the localization of lipoproteins, nothing is known about the role of lolB in cellular processes of bacteria. Here, we find that lolB has multifaceted biological functions in $X c c$. We first demonstrate that mutation in $l o l B$ gene affects bacterial attachment of $X c c$ on abiotic surfaces and host leaves (Fig. 1). As biofilm has been characterized as a virulence trait in many phytopathogenic bacteria [52], our phenotypic evaluation showing the involvement of $l o l B$ in bacterial attachment prompted us to determine whether the lolB gene is associated with pathogenicity of Xcc. Further, regarding to the general role of biofilm formation in promoting bacterial survival against stresses and protecting bacteria from harsh environment, we reasoned that $l o l B$ inactivation might impair the growth ability of $X c c$ under stress treatment. Therefore, the roles of $l o l B$ in pathogenicity, virulence factor production, and stress tolerance were evaluated. We demonstrate that mutation in $l o l B$ results in a substantial reduction in virulence (Fig. 2). The attenuation in virulence of the lolB mutant may result, at least partially if not entirely, from the reduction in extracellular enzyme (including cellulase and mannanase) production (Fig. 3). In addition, the lolB mutant grew much slower under heat stress and in the presence of agents that influence integrity of cell membrane compared with that of the wild-type strain (Fig. 4). Because mutation of lolB led to reductions in extracellular enzyme production and stress tolerance, it seems reasonable to predict that LolB might influence the expression of genes related to these phenotypes. The reporter assay and RT-qPCR analysis (Fig. 5) revealed that mutation in $l o l B$ reduced the expression of genes known to be essential for extracellular enzyme production, stress tolerance, and virulence (engA, manA, prt1, $\operatorname{clp} P$, and $\operatorname{clpX}$ ). It is implying that $l o l B$ might affect the expression of these genes transcriptionally and that the decrease in extracellular enzyme production, bacterial attachment, as well as stress tolerance of the lolB mutant may be attributable to the reduced transcription of these genes.

Lipoprotein is a crucial structural component of the outer membrane, and is central to the physiology of the Gram-negative cell envelope. It is essential for maintaining cellular integrity, envelope stability, and nutrient acquisition, and also plays roles in bacterial pathogenic mechanisms such as attachment, colonization, and invasion $[1,53]$. Bacterial lipoproteins also play an important role in growth and survival of bacteria [54]. Correct localization of lipoproteins is essential for their function, and the Lol system is required for lipoproteins localization $[2,3,5,55]$. Although the involvement of Xcc LolB 
in lipoprotein localization was not experimentally demonstrated, we discerned that several putative lipoprotein encoding genes were significantly up-regulated in the lolB mutant (Table 4) and mutation of lolB decreases the integrity of cell membrane (Fig. 6). Hypothetically, we reasoned that the declined biofilm formation attributable to $l o l B$ inactivation is resulted from changed cell membrane integrity that subsequently affects adhesion ability. It is possible that the lolB mutant has impacts in lipoprotein localization and subsequently the outer membrane lipoprotein profile was altered due to lolB mutation, thereby sensitizing cells to membrane perturbing compounds such as SDS and EDTA. The findings showing impaired tolerance against heat stress and several membrane-perturbing compounds in $l o l B$ mutant could be a plausible explanation for the altered membrane integrity seen in lolB mutant and suggests that Xcc LolB might possess potential role in lipoprotein localization. The mechanism by which the LolB protein acts on lipoprotein outer membrane localization in Xcc remains to be experimentally elucidated.

Bacterial lipoproteins contain a characteristic consensus sequence [LVI][ASTVI][GAS]C known as a lipobox $[2,45]$. Overall, the putative lipoprotein encoding genes tested in this study showed a typical lipobox (Table 4). None of these putative lipoprotein encoding genes had been characterized with respect to lipid modification and membrane localization. The involvement in $X c c$ attachment, virulence, and stress tolerance of these lolB regulated genes is still not known and remains to be explored. It is intriguing that the lolB mutant exhibits an increased expression of several putative lipoprotein encoding genes. Together with the above observations, it is suggested that the inactivation of lolB might alter the outer membrane lipoprotein profiles and such alterations subsequently stimulate the compensatory pathway(s) to increase the expression of lipoprotein related genes to keep lipoprotein homeostasis. It is also pertinent to note that the Xcc LolB possibly affects the transcription of these tested genes indirectly, as the gene product encoded by lolB is not belonging to a regulatory protein. LolB likely influences these genes through an unknown regulatory pathway in Xcc. Further investigation of the potential genes that encoding the unknown regulatory trail that is activated after lolB mutation is needed to confirm the possibility.

\section{Conclusion}

Here, we characterize the lolB gene in $X c c$. By the use of genetic complementation and phenotypic evaluation, we acquired conclusive genetic evidence demonstrated that the lolB plays relevant roles in bacterial attachment, extracellular enzyme production, stress tolerance, as well as virulence of $X c c$. Consistent with phenotypic alterations, the reporter assay and RT-qPCR analysis displayed that the genes encoding major extracellular enzymes, and genes previously reported to be associated with adhesion, stress tolerance, and virulence were reduced in the lolB mutant compared with the wild type. To the best of our knowledge, this is the first work to provide insights of the lolB physiological roles in multifarious cellular processes, including pathogenicity-related functions and environmental stress adaptation.

\section{Abbreviations \\ LB: Luria-Bertani; Lol: lipoprotein outer membrane localization; qPCR: quan- titative real-time polymerase chain reaction; RT: reverse transcription; $X c c$ : Xanthomonas campestris pv. campestris.}

\section{Acknowledgements}

Not applicable

\section{Authors' contributions}

CT and YM managed the grants, supervised the laboratory work, and conceived and design the experiments. $\mathrm{CE}, \mathrm{HC}, \mathrm{CH}$, and $\mathrm{YC}$ performed the experiments. CT and YM analyzed the experimental results, interpreted the data, and wrote the paper. All authors read and approved the final manuscript.

\section{Funding}

This study has been supported by Ministry of Science and Technology of Taiwan (grants No. MOST107-2313-B-166-001-MY3 and MOST1102313-B-166-001) to YMH, and Central Taiwan University of Science and Technology (grant No. CTU109-P-102) to CTL. The authors declare no conflict of interest.

\section{Availability of data and materials}

The data generated and/or analyzed during the current study are included in this article.

\section{Declarations}

Ethics approval and consent to participate

Not applicable

Consent for publication

Not applicable

\section{Competing interests}

The authors declare that they have no competing interest.

Received: 5 July 2021 Accepted: 6 December 2021

Published online: 07 January 2022

\footnotetext{
References

1. Konovalova A, Kahne DE, Silhavy TJ. Outer Membrane Biogenesis. Annu Rev Microbiol. 2017;71:539-56.

2. Konovalova A, Silhavy TJ. Outer membrane lipoprotein biogenesis: Lol is not the end. Philos Trans R Soc Lond B Biol Sci. 2015;370(1679):20150030.

3. Narita SI, Tokuda H. Bacterial lipoproteins; biogenesis, sorting and quality control. Biochim Biophys Acta. 2017;1862(11):1414-23.

4. Grabowicz M: Lipoproteins and their trafficking to the outer membrane. EcoSal Plus 2019, 8(2).

5. Okuda S, Tokuda H. Lipoprotein sorting in bacteria. Annu Rev Microbiol. 2011;65:239-59.

6. Mizutani M, Mukaiyama K, Xiao J, Mori M, Satou R, Narita S, Okuda S, Tokuda H. Functional differentiation of structurally similar membrane
} 
subunits of the $A B C$ transporter LoICDE complex. FEBS Lett. 2013;587(1):23-9.

7. LoVullo ED, Wright LF, Isabella V, Huntley JF, Pavelka MS Jr. Revisiting the Gram-negative lipoprotein paradigm. J Bacteriol. 2015;197(10):1705-15.

8. Remans K, Pauwels K, van Ulsen P, Buts L, Cornelis P, Tommassen J, Savvides SN, Decanniere K, Van Gelder P. Hydrophobic surface patches on LolA of Pseudomonas aeruginosa are essential for lipoprotein binding. J Mol Biol. 2010;401(5):921-30.

9. Tanaka SY, Narita S, Tokuda H. Characterization of the Pseudomonas aeruginosa Lol system as a lipoprotein sorting mechanism. J Biol Chem. 2007;282(18):13379-84.

10. Lorenz C, Dougherty TJ, Lory S. Correct sorting of lipoproteins into the inner and outer bembranes of Pseudomonas aeruginosa by the Escherichia coli LolCDE transport system. mBio. 2019;10(2):e00194.

11. Marin VR, Ferrarezi JH, Vieira G, Sass DC. Recent advances in the biocontrol of Xanthomonas spp. World J Microbiol Biotechnol. 2019;35(5):72.

12. Qian W, Jia Y, Ren SX, He YQ, Feng JX, Lu LF, Sun Q, Ying G, Tang DJ, Tang H, et al. Comparative and functional genomic analyses of the pathogenicity of phytopathogen Xanthomonas campestris pv. campestris. Genome Res. 2005;15(6):757-67.

13. Vicente JG, Holub EB. Xanthomonas campestris pv. campestris (cause of black rot of crucifers) in the genomic era is still a worldwide threat to brassica crops. Mol Plant Pathol. 2013;14(1):2-18.

14. Buttner D, Bonas U. Regulation and secretion of Xanthomonas virulence factors. FEMS Microbiol Rev. 2010;34(2):107-33.

15. Ryan RP, Vorholter FJ, Potnis N, Jones JB, Van Sluys MA, Bogdanove AJ, Dow JM. Pathogenomics of Xanthomonas: understanding bacteriumplant interactions. Nat Rev Microbiol. 2011;9(5):344-55.

16. Liu YC, Wang SC, Yu YJ, Fung KM, Yang MT, Tseng YH, Tsai SF, Sun HS, Lyu PC, Chou SH. Complete Genome Sequence of Xanthomonas campestris pv. campestris Strain 17 from Taiwan. Genome Announc. 2015;3(6):e01466.

17. Vorholter FJ, Schneiker S, Goesmann A, Krause L, Bekel T, Kaiser O, Linke B, Patschkowski T, Ruckert C, Schmid J, et al. The genome of Xanthomonas campestris pv. campestris $\mathrm{B} 100$ and its use for the reconstruction of metabolic pathways involved in xanthan biosynthesis. J Biotechnol. 2008;134(1-2):33-45.

18. da Silva AC, Ferro JA, Reinach FC, Farah CS, Furlan LR, Quaggio RB, Monteiro-Vitorello CB, Van Sluys MA, Almeida NF, Alves LM, et al. Comparison of the genomes of two Xanthomonas pathogens with differing host specificities. Nature. 2002;417(6887):459-63.

19. Liao CT, Chiang YC, Hsiao YM. Functional characterization and proteomic analysis of IolA in Xanthomonas campestris pv. campestris. BMC Microbiol. 2019;19(1):20.

20. Miller JH. Experiments in molecular genetics. Cold Spring Harbor ,N. Y: Cold Spring Harbor Laboratory; 1972.

21. Fu JF, Tseng YH. Construction of lactose-utilizing Xanthomonas campestris and production of xanthan gum from whey. Appl Environ Microbiol. 1990;56(4):919-23.

22. Yang BY, Tseng YH. Production of exopolysaccharide and levels of protease and pectinase activity in pathogenic and non-pathogenic strains of Xanthomonas campestris pv. campestris. Bot Bull Acad Sin. 1988;29:93-9.

23. Yen MR, Lin NT, Hung CH, Choy KT, Weng SF, Tseng YH. oriC region and replication termination site, dif, of the Xanthomonas campestris pv. campestris 17 chromosome. Appl Environ Microbiol. 2002;68(6):2924-33.

24. Keen NT, Tamaki S, Kobayashi D, Trollinger D. Improved broad-hostrange plasmids for DNA cloning in gram-negative bacteria. Gene. 1988;70(1):191-7.

25. Lee TC, Chen ST, Lee MC, Chang CM, Chen CH, Weng SF, Tseng YH. The early stages of filamentous phage phiLf infection require the host transcription factor. Clp J Mol Microbiol Biotechnol. 2001;3(3):471-81.

26. Liao CT, Liu YF, Chiang YC, Lo HH, Du SC, Hsu PC, Hsiao YM. Functional characterization and transcriptome analysis reveal multiple roles for prc in the pathogenicity of the black rot pathogen Xanthomonas campestris pv. campestris. Res Microbiol. 2016;167(4):299-312.

27. Li CE, Liao CT, Lo HH, Hsiao YM. Functional characterization and transcriptional analysis of $\mathrm{clpP}$ of Xanthomonas campestris pv. campestris. Curr Microbiol. 2020;77(10):2876-85.
28. Hsiao YM, Liao HY, Lee MC, Yang TC, Tseng YH. Clp upregulates transcription of engA gene encoding a virulence factor in Xanthomonas campestris by direct binding to the upstream tandem Clp sites. FEBS Lett. 2005;579(17):3525-33.

29. Sambrook J, Fritsch EF, Maniatis T. Molecular Cloning: a laboratory manual. 2nd ed. N. Y: Cold Spring Harbor Press, Cold Spring Harbor; 1989.

30. Wang TW, Tseng YH. Electrotransformation of Xanthomonas campestris by RF DNA of filamentous phage fLf. Lett Appl Microbiol. 1992;14(2):65-8.

31. Lo HH, Liao CT, Li CE, Chiang YC, Hsiao YM. The clpX gene plays an important role in bacterial attachment, stress tolerance, and virulence in Xanthomonas campestris pv. campestris. Arch Microbiol. 2020;202(3):597-607.

32. Hsiao YM, Liu YF, Fang MC, Song WL. XCC2731, a GGDEF domain protein in Xanthomonas campestris, is involved in bacterial attachment and is positively regulated by Clp. Microbiol Res. 2011;166(7):548-65.

33. Feng J, Yee R, Zhang S, Tian L, Shi W, Zhang WH, Zhang Y. A Rapid GrowthIndependent Antibiotic Resistance Detection Test by SYBR Green/Propidium lodide Viability Assay. Front Med (Lausanne). 2018;5:127.

34. Feng J, Wang T, Zhang S, Shi W, Zhang Y. An optimized SYBR Green I/PI assay for rapid viability assessment and antibiotic susceptibility testing for Borrelia burgdorferi. PLoS One. 2014;9(11):e111809.

35. Bogdanove AJ, Koebnik R, Lu H, Furutani A, Angiuoli SV, Patil PB, Van Sluys MA, Ryan RP, Meyer DF, Han SW, et al. Two new complete genome sequences offer insight into host and tissue specificity of plant pathogenic Xanthomonas spp. J Bacteriol. 2011;193(19):5450-64.

36. Thieme F, Koebnik R, Bekel T, Berger C, Boch J, Buttner D, Caldana C, Gaigalat L, Goesmann A, Kay S, et al. Insights into genome plasticity and pathogenicity of the plant pathogenic bacterium Xanthomonas campestris pv. vesicatoria revealed by the complete genome sequence. J Bacteriol. 2005;187(21):7254-66.

37. Richard D, Boyer C, Lefeuvre P, Canteros BI, Beni-Madhu S, Portier P, Pruvost O. Complete Genome Sequences of Six Copper-Resistant Xanthomonas Strains Causing Bacterial Spot of Solaneous Plants, Belonging to $X$. gardneri, $X$. euvesicatoria, and $X$. vesicatoria, Using Long-Read Technology. Genome Announc. 2017;5(8):e01693.

38. Lee BM, Park YJ, Park DS, Kang HW, Kim JG, Song ES, Park IC, Yoon UH, Hahn JH, Koo BS, et al. The genome sequence of Xanthomonas oryzae pathovar oryzae KACC10331, the bacterial blight pathogen of rice. Nucleic Acids Res. 2005;33(2):577-86.

39. Dow JM, Crossman L, Findlay K, He YQ, Feng JX, Tang JL. Biofilm dispersal in Xanthomonas campestris is controlled by cell-cell signaling and is required for full virulence to plants. Proc Natl Acad Sci U S A. 2003;100(19):10995-1000.

40. Chan JW, Goodwin PH. The molecular genetics of virulence of Xanthomonas campestris. Biotechnol Adv. 1999;17(6):489-508.

41. Liao CT, Du SC, Lo HH, Hsiao YM. The galU gene of Xanthomonas campestris pv. campestris is involved in bacterial attachment, cell motility, polysaccharide synthesis, virulence, and tolerance to various stresses. Arch Microbiol. 2014;196(10):729-38.

42. Chen YY, Wu CH, Lin JW, Weng SF, Tseng YH. Mutation of the gene encoding a major outer-membrane protein in Xanthomonas campestris pv. campestris causes pleiotropic effects, including loss of pathogenicity. Microbiology. 2010;156(Pt 9):2842-54.

43. Hsiao YM, Liu YF, Fang MC, Tseng YH. Transcriptional regulation and molecular characterization of the manA gene encoding the biofilm dispersing enzyme mannan endo-1,4-beta-mannosidase in Xanthomonas campestris. J Agric Food Chem. 2010;58(3):1653-63.

44. Hsiao YM, Tseng YH. Transcription of Xanthomonas campestris prt1 gene encoding protease 1 increases during stationary phase and requires global transcription factor Clp. Biochem Biophys Res Commun. 2002;295(1):43-9.

45. Babu MM, Priya ML, Selvan AT, Madera M, Gough J, Aravind L, Sankaran K. A database of bacterial lipoproteins (DOLOP) with functional assignments to predicted lipoproteins. J Bacteriol. 2006;188(8):2761-73.

46. Mistry J, Chuguransky S, Williams L, Qureshi M, Salazar GA, Sonnhammer ELL, Tosatto SCE, Paladin L, Raj S, Richardson LJ, et al. Pfam: The protein families database in 2021. Nucleic Acids Res. 2021;49(D1):D412-9.

47. Tanaka K, Matsuyama SI, Tokuda H. Deletion of /o/B, encoding an outer membrane lipoprotein, is lethal for Escherichia coli and causes accumulation of lipoprotein localization intermediates in the periplasm. J Bacteriol. 2001;183(22):6538-42. 
48. Matsuyama S, Yokota N, Tokuda H. A novel outer membrane lipoprotein, LolB (HemM), involved in the LolA (p20)-dependent localization of lipoproteins to the outer membrane of Escherichia coli. EMBO J. 1997;16(23):6947-55.

49. Wada R, Matsuyama S, Tokuda H. Targeted mutagenesis of five conserved tryptophan residues of LolB involved in membrane localization of Escherichia coli lipoproteins. Biochem Biophys Res Commun. 2004;323(3):1069-74.

50. Hayashi Y, Tsurumizu R, Tsukahara J, Takeda K, Narita SI, Mori M, Miki $\mathrm{K}$, Tokuda H. Roles of the protruding loop of factor B essential for the localization of lipoproteins (LoIB) in the anchoring of bacterial triacylated proteins to the outer membrane. J Biol Chem. 2014;289(15):10530-9.

51. Petersen TN, Brunak S, von Heijne G, Nielsen H. SignalP 4.0: discriminating signal peptides from transmembrane regions. Nat Methods. 2011;8(10):785-6.

52. Danhorn T, Fuqua C. Biofilm formation by plant-associated bacteria. Annu Rev Microbiol. 2007;61:401-22.

53. Zuckert WR. Secretion of bacterial lipoproteins: through the cytoplasmic membrane, the periplasm and beyond. Biochim Biophys Acta. 2014:1843(8):1509-16.

54. Kovacs-Simon A, Titball RW, Michell SL. Lipoproteins of bacterial pathogens. Infect Immun. 2011;79(2):548-61.

55. Narita S, Matsuyama S, Tokuda H. Lipoprotein trafficking in Escherichia coli. Arch Microbiol. 2004;182(1):1-6.

\section{Publisher's Note}

Springer Nature remains neutral with regard to jurisdictional claims in published maps and institutional affiliations.

- fast, convenient online submission

- thorough peer review by experienced researchers in your field

- rapid publication on acceptance

- support for research data, including large and complex data types

- gold Open Access which fosters wider collaboration and increased citations

- maximum visibility for your research: over $100 \mathrm{M}$ website views per year

At BMC, research is always in progress.

Learn more biomedcentral.com/submissions 